\title{
Occurrence of Residual Cancer Within Re-excisions After Subcutaneous Mastectomy of Invasive Breast Cancer and Ductal Carcinoma In Situ - A Retrospective Analysis
}

\author{
CAROLINE PAHMEYER ${ }^{1}$, ANIKA SCHABLACK ${ }^{1}$, DOMINIK RATIU ${ }^{1}$, \\ FABINSHY THANGARAJAH ${ }^{1}$, SEBASTIAN LUDWIG ${ }^{1}$, BERTHOLD GRUETTNER ${ }^{1}$, \\ PETER MALLMANN ${ }^{1}$, WOLFRAM MALTER ${ }^{1}$, MATHIAS WARM $^{2}$ and CHRISTIAN EICHLER ${ }^{1}$ \\ ${ }^{1}$ Department of Gynecology and Obstetrics, University of Cologne, Cologne, Germany; \\ ${ }^{2}$ Breast Cancer Center, Municipal Hospital Holweide, Cologne, Germany
}

\begin{abstract}
Background/Aim: Surgical margin status remains an important determinant for recurrence of invasive breast cancer and ductal carcinoma in situ. We compared the number of positive margins in initial histology with rates of residual tumor in re-excision specimens. Furthermore, we analysed cost-effectiveness of re-excisions. Patients and Methods: 101 patients treated with secondary surgery were included. The first group underwent breast conserving surgery and secondary mastectomy. The second group was primarily treated with subcutaneous mastectomy followed by secondary surgery. Results: Within the first group, $22.7 \%$ did not show residual tumor in the re-excision specimen. Of the second group, $54.3 \%$ had no residual tumor. Consequentially $45.7 \%$ needed a re-excision to achieve RO status. Costeffectiveness was determined as secondary endpoint. If a patient needs a secondary mastectomy the hospital gains $602,65 €$ in comparison to a primary breast conserving operation. Conclusion: In every second patient who had first received a subcutaneous mastectomy, no tumor could be detected in the secondary operation despite a previous $R I$ status.
\end{abstract}

Surgical margin status ("no ink on tumor") remains an important determinant for local recurrence of ductal carcinoma in situ (DCIS) and invasive breast cancer (IBC) $(1,2)$. Whether breast conserving surgery (BCS) or

This article is freely accessible online.

Correspondence to: Dr. med. Caroline Pahmeyer, University Hospital Cologne, Department of Gynecology and Obstetrics, Medical Faculty, Kerpener Str. 34, 50931 Cologne, Germany. Tel: +49 2214784910 , Fax: +49 2214786729, e-mail: Caroline.pahmeyer@uk-koeln.de

Key Words: Subcutaneous mastectomy, residual cancer, re-excisions. mastectomy is performed, depends on tumor size, size of the breast, patient consent and tumor biology. Positive margins after BCS or mastectomy subsequently leads to secondary surgeries $(1,3)$. Those are unavoidable to lower the risk of local recurrence (4-6). Of the 66,970 patients treated with surgery for DCIS or IBC in 2018, 10,070 patients underwent re-excision in Germany (7). Literature shows residual tumor rates of $33-73 \%$ within re-excision (Table I). Some studies differentiate between DCIS and IBC, but often don't distinguish between type of primary operative strategy.

The primary endpoint in this study was re-excision-rates for DCIS and IBC depending on the operative strategy. We provide data regarding the significance of residual tumor within re-excisions after primary surgery with positive margins.

The "diagnosis related group"-system (DRG) in Germany stipulates that even in the case of a re-operation only the costliest procedure is invoiced. The secondary endpoint in this study was the cost-effectiveness of the secondary surgery.

\section{Patients and Methods}

Patients treated with secondary surgery between June 2017 and March 2019 in the municipal Hospital of Cologne, Holweide, due to positive or close margins within the initial surgery were included in this study. Tumor conference protocols provided information on tumor biology, tumor size, neoadjuvant chemotherapy, primary surgery, pathology results and planned procedures.

Regarding the financial implications, the "Webgrouper" of the DRG-Research-Group provides the possibility of classifying the complete hospital stay of breast cancer patients with surgery into diagnosis-related flat rates per case. This results in a total charge for the medical service within one case. The "Webgrouper" is an open source and can be used free of charge, while hospitals use certain certified software programs as groupers. The algorithms of the groupers are nevertheless the same. Within this "Webgrouper", patient related data as age, date of hospitalization and date of 
Table I. An overview of available literature on residual tumor findings within re-excisions in invasive breast cancer (IBC), ductal carcinoma in situ (DCIS) treated with breast conserving surgery (BCS) or mastectomy.

\begin{tabular}{|c|c|c|c|c|c|}
\hline & Year & Study design & $\begin{array}{l}\text { Number } \\
\text { of cases }\end{array}$ & Detail & $\begin{array}{l}\text { Residual tumor } \\
\text { in re-excision }\end{array}$ \\
\hline Krishnamurthy et al. (10) & 2019 & Single institution & 210 & Only BCS & $\begin{array}{l}40 \% \text { (DCIS) } \\
19 \% \text { (IBC) }\end{array}$ \\
\hline Lai et al. (11) & 2018 & $\begin{array}{c}\text { Database analysis } \\
\text { Taiwan }\end{array}$ & 2050 & $\begin{array}{l}\text { BCS and mastectomy } \\
\text { (no differentiation) }\end{array}$ & $\begin{array}{c}73 \% \text { (DCIS) } \\
42.3 \% \text { (IBC) } \\
53 \% \text { (BCS) }\end{array}$ \\
\hline Biglia et al. (8) & 2014 & Single institution & 1339 & Only BCS & $62.9 \%$ (DCIS and IBC) \\
\hline Cellini et al. (12) & 2004 & Single institution & 276 & Only BCS & $63 \%$ (DCIS and IBC) \\
\hline Kurniawan et al. (13) & 2008 & Single institution & 281 & Only BCS & $33.1 \%$ (DCIS and IBC) \\
\hline Findlay-Shirras et al. (14) & 2018 & $\begin{array}{c}\text { Analysis of Manitoba } \\
\text { Cancer registry }\end{array}$ & 556 & Only BCS & $\begin{array}{c}62.7 \% \\
50 \% \text { (lumpectomy) } \\
83 \% \text { (mastectomy) } \\
\text { (DCIS and IBC) }\end{array}$ \\
\hline Atalay et al. (15) & 2012 & Single institution & 104 & Only BCS & $\begin{array}{c}45.2 \% \text { (Invasive ductal } \\
\text { carcinoma) }\end{array}$ \\
\hline
\end{tabular}

Table II. Inclusion and exclusion criteria applied in this study.

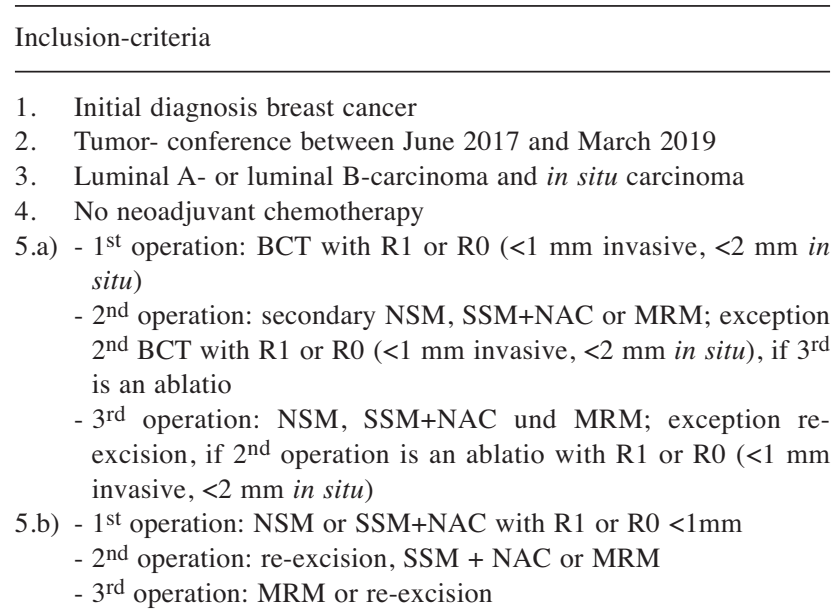

Exclusion-criteria

1. HER2-subtype and triple negative breast cancer

2. Neoadjuvant chemotherapy

3. Primary BCT with $\mathrm{R} 1$ or $\mathrm{R} 0$ ( $<1 \mathrm{~mm}$ invasive, $<2 \mathrm{~mm}$ in situ) and secondary re-excision with R0

discharge from hospital, main diagnoses (ICD: International Statistical Classification of Diseases and Related Health Problems) as well as procedures are coded and classified into groups. Table II shows in- and ex-clusion criteria applied in this study.

Patients with metastases as well as recurrent cancer were excluded. Patients with a Her2-subtype or triple negative breast cancer normally undergo neoadjuvant chemotherapy. Those patients were excluded, because a definite estimation of margins within total
Table III. Patient characteristics.

\begin{tabular}{lrr}
\hline Characteristic & $\mathrm{N}$ & $\%$ \\
\hline Age & & \\
$\leq 40$ & 5 & 5.0 \\
$41-50$ & 25 & 24.8 \\
$51-60$ & 34 & 33.7 \\
$61-70$ & 30 & 29.7 \\
$\geq 71$ & 7 & 6.9 \\
Menopause status & & \\
Pre-menopausal & 42 & 41.6 \\
Post-menopausal & 59 & 58.4 \\
Side & & \\
Right & 52 & 51.5 \\
Left & 49 & 48.5 \\
Tumor & & \\
Invasive (total) & 81 & 80.2 \\
$\quad$ Ductal & 54 & 66.7 \\
$\quad$ Lobular & 22 & 27.2 \\
$\quad$ Invasive mixed & 5 & 6.2 \\
Invasive without in situ component & 11 & 13.6 \\
Invasive with in situ component & 60 & 74.1 \\
Invasive with B3 lesions & 10 & 12.3 \\
In situ & 20 & 19.8 \\
\hline$\quad$ & & \\
\hline
\end{tabular}

remission is not possible. Age, menopause status or adjuvant chemotherapy had no influence. Invasive breast cancer as well as IBC with DCIS component and only DCIS were included.

The first group of patients was treated with BCS. Histological results show margin positivity or close margins within the surgical specimen. The following surgical strategy was either secondary mastectomy or re- excision with again positive margins followed by a third operation (mastectomy). 
Pahmeyer et al: Occurrence of Residual Cancer Within Re-excisions

Table IV. An overview of available literature on residual tumor findings within re-excisions in invasive breast cancer (IBC), ductal carcinoma in situ (DCIS) treated with breast conserving surgery (BCS) or mastectomy.

\begin{tabular}{|c|c|c|c|c|c|c|c|}
\hline $\begin{array}{l}1^{\text {st }} \\
\text { Operation }\end{array}$ & $\begin{array}{c}2^{\text {nd }} \\
\text { Operation }\end{array}$ & $\begin{array}{l}\text { Total } \\
(\%)\end{array}$ & $\begin{array}{l}\text { Residual } \\
\text { tumor }\end{array}$ & $\begin{array}{l}\text { No residual } \\
\text { tumor }\end{array}$ & $\begin{array}{c}3^{\text {rd }} \\
\text { Operation }\end{array}$ & Total & $\begin{array}{l}\text { No residual } \\
\text { tumor }\end{array}$ \\
\hline BCS & MRM & $11(16.7)$ & 7 (63.6) & $4(36.4)$ & & & \\
\hline $\mathrm{BCS}$ & NSM & $45(68.2)$ & $34(75.6)$ & $11(24.4)$ & $\begin{array}{l}\text { Re-excision } \\
\text { MRM }\end{array}$ & $\begin{array}{l}3 \\
1\end{array}$ & $\begin{array}{c}3(100) \\
0(0)\end{array}$ \\
\hline BCS & $\mathrm{SSM}+\mathrm{NAC}$ & $3(4.5)$ & $3(100)$ & $0(0)$ & & & \\
\hline BCS & Re-excision & 7 (10.6) & $7(100)$ & $0(0)$ & $\begin{array}{c}\text { NSM } \\
\text { SSM+NAC }\end{array}$ & $\begin{array}{l}6 \\
1\end{array}$ & $\begin{array}{l}1(16.7) \\
1(100)\end{array}$ \\
\hline Total & & $66(100)$ & $51(77.3)$ & $15(22.7)$ & & 11 & $5(45.5)$ \\
\hline
\end{tabular}

The second group of patients were initially treated with subcutaneous mastectomy (NSM or SSM+NAC) and showed positive or close margins (Table II).

Patients primarily treated with BCS followed by re-excision showing no ink on tumor were excluded.

Written informed consent was obtained from all patients. A copy of the written statement may be available for review by the editor of this journal at any time. The tumor board consisted of several gynecological/surgical oncologists, internal medicine oncologists, radiologists, radiation therapists as well as psycho-oncologists and breast care nurses.

\section{Results}

A total of 101 patients were included in this study. Table III shows patients characteristics. The surgical strategy was chosen based on tumor size, multifocal or multicentric appearance in preoperative MRI, mammography or ultrasound. Postoperative tumor size was determined by histological examination. Within 88 cases clinical T-status was compared with histological T-status. In $38.6 \%$ of the cases tumor size within the surgical specimen was bigger or bigger with multifocal appearance compared to the clinical tumor size. In $7 \%$, postoperative status was smaller or smaller with multifocal appearance.

We analyzed the significance of residual free specimen within re-excisions after margin positive status depending on the surgical strategy.

Residual tumor within the second operation was not detected in $22.7 \%$ of the patients in the first group. Five patients who underwent a third operation did not show residual tumor (Table IV).

Within the second group of patients, $54.3 \%$ showed no residual tumor within the surgical specimen of the second operation. Four out of seven patients who underwent a third operation had no residual tumor. Initially treated with NSM (nipple sparing mastectomy) or SSM (skin sparing mastectomy)+NAC (nipple areola complex), 31.4\% of those patients underwent a secondary MRM due to margin positivity but $63.6 \%$ of them did not show residual tumor in this operation.

The results of the second group with patients who initially underwent mastectomy are shown in Table V.

Furthermore, we analyzed the correlation between the character of the tumor and re-excision findings. Three groups were distinguished: invasive carcinoma, DCIS and invasive carcinoma with DCIS-component.

By providing the R-status of the histopathological findings after primary surgery, it could be verified whether tumor residuals are still found in the surgical specimens of the second surgery. The R status is defined as R1 or as R0 with minimum distance to positive margins. In invasive carcinoma, the minimum distance to margins should not be less than $1 \mathrm{~mm}$, in DCIS at best even $2 \mathrm{~mm}$ or more. Our results are summarized in Table VI.

Seventeen of 21 patients with invasive carcinoma showed R1-status. In $41.2 \%$ of these patients, "no ink on tumor" could be found in secondary surgery specimen.

In $94.1 \%$ of the patients showing R1-status after primary surgery for DCIS, residuals of the tumor were shown in secondary surgery.

There were 60 patients with invasive carcinoma and DCIScomponent at the same time. 20 of these patients had positive margins regarding the invasive component. Within the secondary surgery specimen $65 \%$ showed "no ink on tumor". Regarding the DCIS-component, 19 of 60 patients had R1status. However, $68.4 \%$ still contained residual tumor.

\section{Discussion}

Surgical margin status remains the most important determinant for local recurrence in invasive breast cancer and ductal carcinoma in situ $(3,6,8)$. Breast conserving surgery has become a standard procedure besides subcutaneous mastectomy. Patients showing positive margins after initial surgery should receive a second operation to achieve R0status and therefore lower the risk of local recurrence. 
in vivo $34:$ 2015-2019 (2020)

Table V. An overview of the results within the group who was subjected to NSM or SSM+MAK as initial surgery in total and (\%).

\begin{tabular}{|c|c|c|c|c|c|c|c|}
\hline $\begin{array}{l}1^{\text {st }} \\
\text { Operation }\end{array}$ & $\begin{array}{c}2^{\text {nd }} \\
\text { Operation }\end{array}$ & $\begin{array}{l}\text { Total } \\
(\%)\end{array}$ & $\begin{array}{l}\text { Residual } \\
\text { tumor }\end{array}$ & $\begin{array}{l}\text { No residual } \\
\text { tumor }\end{array}$ & $\begin{array}{c}3^{\text {rd }} \\
\text { Operation }\end{array}$ & Total & $\begin{array}{l}\text { No residual } \\
\text { tumor }\end{array}$ \\
\hline NSM & MRM & $9(27.3)$ & 3 & $6(66.7)$ & Re-excision & 2 & $2(100)$ \\
\hline NSM & Re-excision & $22(62.9)$ & 10 & $12(54.5)$ & $\begin{array}{c}\text { Re-excision } \\
\text { MRM }\end{array}$ & $\begin{array}{l}2 \\
3\end{array}$ & $\begin{array}{c}1(50) \\
1(33.3)\end{array}$ \\
\hline NSM & SSM+MAK & $2(5.7)$ & 2 & $0(0)$ & & & \\
\hline SSM+MAK & MRM & $2(5.7)$ & 1 & $1(50)$ & NSM & 6 & $1(16.7)$ \\
\hline Total & $\begin{array}{c}\text { SSM+MAK } \\
\text { Re-excision } \\
\text { MRM }\end{array}$ & $\begin{aligned} 35 & (100) \\
2 & (5.7) \\
22 & (62.9) \\
11 & (31.4)\end{aligned}$ & $\begin{array}{c}16 \\
2 \\
10 \\
4\end{array}$ & $\begin{array}{c}19(54.3) \\
0(0.0) \\
12(54.5) \\
7(63.6)\end{array}$ & & 7 & $4(57.1)$ \\
\hline
\end{tabular}

We compared the number of positive margins in initial histology with the rates of residual tumor in re-excision specimen depending on the operative strategy.

Additionally, the cost-effectiveness of secondary surgery was determined as secondary endpoint in this study. In case of a re-operation only the costliest procedure for each patient can be invoiced. The effect of these additional costs due to re-operations were examined.

In this study, eleven patients who underwent BCS were treated with a secondary MRM. Of these, 36.4\% did not show residual tumor within the surgical specimen but were exposed to the perioperative risk of a second surgery and had to cope with the loss of their breast.

Consequently, in four cases this surgical procedure was not adequate as a follow-up operation from a health finances perspective. The fee for a BCS is $4.700,63 €$. Since both hospital stays are combined, the secondary MRM causes an increase in the remuneration to $€ 5,303.28$, however, the BCS is no longer considered. If the costs of two hospital stays with two operations are represented with one DRG, the revenue after deduction of costs might be lower than the revenue after only the first surgery. Re-excisions might not be profitable for hospitals.

In every second patient who had first received a subcutaneous mastectomy, no tumor could be detected in the secondary operation despite previous positive margins. As already mentioned in the first group, case revenues for all operations are considered as one hospital stay. Thus, after one or two further operations, they result in the same amount as after the first operation. In case of NSM, the amount will not be higher than $7.153,75 €$. Costs, such as preoperative examinations, preoperative and postoperative discussion in the tumour conference, preoperative marking or the histopathological examination of the surgical specimen might not be covered.

On behalf of the patients but also considering the profitability of the hospital, further approaches must be developed in order to avoid unnecessary re-excisions.
Table VI. An overview of re-excision findings in correlation to the character of the tumor.

\begin{tabular}{|c|c|c|c|c|}
\hline & & \multicolumn{3}{|c|}{ Invasive/B3 ( $\mathrm{N}=21)$} \\
\hline & & \multicolumn{2}{|l|}{ Residuals } & No residuals \\
\hline $\begin{array}{l}\mathrm{R} 1 \quad(\mathrm{~N}=17) \\
\mathrm{R} 0(<1 \mathrm{~mm})\end{array}$ & $\mathrm{N}=4$ ) & \multicolumn{2}{|l|}{$10(58.8 \%)$} & $\begin{array}{l}7(41.2 \%) \\
3(75.0 \%)\end{array}$ \\
\hline & \multicolumn{4}{|c|}{$\begin{array}{c}\text { Invasive carcinoma } \\
\text { with DCIS-component }(\mathrm{n}=60)\end{array}$} \\
\hline & $\mathrm{R} 1$ & $\mathrm{R} 0(<1 \mathrm{~mm})$ & Residuals & No residuals \\
\hline $\begin{array}{l}\text { Invasive } \\
\text { component }\end{array}$ & $20(33.3 \%)$ & $14(23.3 \%)$ & $\begin{array}{c}7(35 \%) \\
3(21.4 \%)\end{array}$ & $\begin{array}{c}13(65 \%) \\
11(78.6 \%)\end{array}$ \\
\hline $\begin{array}{l}\text { DCIS } \\
\text { component }\end{array}$ & $19(31.7 \%)$ & $8(13.3 \%)$ & $\begin{array}{c}13(68.4 \%) \\
5(62.5 \%)\end{array}$ & $\begin{array}{l}6(31.6 \%) \\
3(37.5 \%)\end{array}$ \\
\hline
\end{tabular}

MRI diagnostics are not yet part of standard preoperative imaging, as the majority of breast tumors can be imaged mammographically. Studies have shown that in some cases a multifocal growth of the tumor occurred as pathological finding but were not diagnosed preoperatively (9). A preoperative MRIimaging could identify a multifocal tumor which cannot be visualized either sonographically or mammographically. This consequently might influence the surgical strategy.

We showed that re-excision specimens often do not show residual tumor. In some cases, complex oncoplastic procedures are used to achieve "no ink on tumor" and therefore reduce the risk of recurrence. This also means those women are exposed to the risks of surgery for a second or even a third time.

In order to prevent the perioperative risk of a re-excision for each patient, intraoperative margin assessment techniques to minimize margin positivity are needed. 


\section{Conflicts of Interest}

The Authors declare no conflicts of interest regarding this study.

\section{Authors' Contributions}

Caroline Pahmeyer: writing, editing, data collection; Anika Schablack: data collection statistical analysis, trial development; Fabinshy Thangarajah: writing, editing; Dominik Ratiu: writing, editing; Sebastian Ludwig: writing, editing; Berthold Gruettner: writing, editing; Wolfram Malter: writing, editing; Peter Mallmann: writing, editing; Mathias Warm: writing, editing; Christian Eichler: writing, editing, data collection, statistical analysis, trial development.

\section{References}

1 O'Kelly Priddy CM, Forte VA and Lang JE: The importance of surgical margins in breast cancer. J Surg Oncol 113(3): 256-263, 2016. PMID: 26394558. DOI: 10.1002/jso.24047

2 Sigal-Zafrani B, Lewis JS, Clough KB, Vincent-Salomon A, Fourquet A, Meunier M, Falcou MC, Sastre-Garau X and Institut Curie Breast Study G: Histological margin assessment for breast ductal carcinoma in situ: Precision and implications. Mod Pathol 17(1): 81-88, 2004. PMID: 14657957. DOI: 10.1038/ modpathol.3800019

3 Freedman G, Fowble B, Hanlon A, Nicolaou N, Fein D, Hoffman J, Sigurdson E, Boraas M and Goldstein L: Patients with early stage invasive cancer with close or positive margins treated with conservative surgery and radiation have an increased risk of breast recurrence that is delayed by adjuvant systemic therapy. Int J Radiat Oncol Biol Phys 44(5): 1005-1015, 1999. PMID: 10421533. DOI: 10.1016/s0360-3016(99)00112-1

4 Sanchez C, Brem RF, McSwain AP, Rapelyea JA, Torrente J and Teal CB: Factors associated with re-excision in patients with early-stage breast cancer treated with breast conservation therapy. Am Surg 76(3): 331-334, 2010. PMID: 20349668.

5 Mechera R, Viehl CT and Oertli D: Factors predicting in-breast tumor recurrence after breast-conserving surgery. Breast Cancer Res Treat 116(1): 171-177, 2009. PMID: 18815880. DOI: 10.1007/s10549-008-0187-y

6 Houssami N, Macaskill P, Marinovich ML, Dixon JM, Irwig L, Brennan ME and Solin LJ: Meta-analysis of the impact of surgical margins on local recurrence in women with early-stage invasive breast cancer treated with breast-conserving therapy. Eur J Cancer 46(18): 3219-3232, 2010. PMID: 20817513. DOI: $10.1016 /$ j.ejca.2010.07.043
7 Gesundheitswesen Bundesasuwertung zum Erfassungsjahr Mammachirurgie 2018. Available at: https://iqtig.org/downloads/ a u s wertung/2018/18 n 1 ma m ma/Q S K H_ $18 \mathrm{n} 1$ MAMMA_2018_BUAW_V02_2019-07-23.pdf

8 Biglia N, Ponzone R, Bounous VE, Mariani LL, Maggiorotto F, Benevelli C, Liberale V, Ottino MC and Sismondi P: Role of reexcision for positive and close resection margins in patients treated with breast-conserving surgery. Breast 23(6): 870-875, 2014. PMID: 25305040. DOI: 10.1016/j.breast.2014.09.009

9 Kuhl CK: The changing world of breast cancer: A radiologist's perspective. Invest Radiol 50(9): 615-628, 2015. PMID: 26083829. DOI: 10.1097/RLI.0000000000000166

10 Krishnamurthy K, Febres-Aldana CA, Alghamdi S, Mesko T, Paramo J and Poppiti RJ: Comparative analysis of margin status in breast conservation surgery and its correlation with subsequent re-excision findings. Pathologica 111(1): 31-36, 2019. PMID: 31217620. DOI: 10.32074/1591-951X-64-18

11 Lai HW, Huang RH, Wu YT, Chen CJ, Chen ST, Lin YJ, Chen DR, Lee CW, Wu HK, Lin HY and Kuo SJ: Clinicopathologic factors related to surgical margin involvement, reoperation, and residual cancer in primary operable breast cancer - an analysis of 2050 patients. Eur J Surg Oncol 44(11): 1725-1735, 2018. PMID: 30120037. DOI: 10.1016/j.ejso.2018.07.056

12 Cellini C, Hollenbeck ST, Christos P, Martins D, Carson J, Kemper S, Lavigne E, Chan E and Simmons R: Factors associated with residual breast cancer after re-excision for close or positive margins. Ann Surg Oncol 11(10): 915-920, 2004. PMID: 15383425. DOI: 10.1245/ASO.2004.12.037

13 Kurniawan ED, Wong MH, Windle I, Rose A, Mou A, Buchanan M, Collins JP, Miller JA, Gruen RL and Mann GB: Predictors of surgical margin status in breast-conserving surgery within a breast screening program. Ann Surg Oncol 15(9): 2542-2549, 2008. PMID: 18618180. DOI: 10.1245/s10434-008-0054-4

14 Findlay-Shirras LJ, Outbih O, Muzyka CN, Galloway K, Hebbard PC and Nashed M: Predictors of residual disease after breast conservation surgery. Ann Surg Oncol 25(7): 1936-1942, 2018. PMID: 29748884. DOI: 10.1245/s 10434-018-6454-1

15 Atalay C and Irkkan C: Predictive factors for residual disease in re-excision specimens after breast-conserving surgery. Breast $\mathrm{J}$ 18(4): 339-344, 2012. PMID: 22616572. DOI: 10.1111/j.15244741.2012.01249.x
Received April 8, 2020

Revised April 17, 2020

Accepted April 18, 2020 